\title{
Optimum Unbraced Length Ratios of Slender Steel Sections
}

\author{
Saleem M. Umair, Q. Hisham, and Zahid A. Siddiqi
}

\begin{abstract}
To get minimum weight design of steel structures, selection of suitable steel section for design of a steel member is always been a point of great interest from a designer's point of view. Because of thin flanges and webs slender sections are lighter as compared to compact and non-compact sections. Aim of this research study is to determine the optimum unbraced length of slender steel sections under bending and compression effects. Required objectives are achieved by selecting a wide range of steel sections having non compact to slender webs and flanges. After making a careful selection of different steel sections, each steel section is analyzed under compression and bending for a given unbraced length of steel member and optimum values of flange and web slenderness are determined. Same procedure is repeated for all selected steel sections for different unbraced length ratios. Results have determined the optimum values of flange and web slenderness which can lead towards the minimum weight and cost of steel structures.
\end{abstract}

Index Terms-Flange slenderness ratio, optimum unbraced length ratio, pre-engineered buildings, web slenderness ratio.

\section{INTRODUCTION}

Minimum weight design of steel structure has been always the area of great interest of most of the researchers to get lighter and cheaper steel sections. This idea was further strengthened with the development of Pre Engineered Steel Industry. A typical Pre Engineered Steel Building (PEB) consists of a steel frame as primary framing and cold form purlins and sheeting for roof and walls as secondary framing.

Cold formed sections and cold formed sheeting's profiles are thin walled steel section with highly slender webs and flanges. In PEB structures, web slenderness of the steel section mostly lies in slender range and flange slenderness varies from compact range to slender ranges. In case of cold formed sections, thickness is very less and these sections lie in highly slender range. Fig. 1 shows a typical PEB structure with built-up frames as primary framing and cold formed Zsections as purlin and roof sheeting. Fig. 2 shows different types of sections used in the PEB industry. Fig. 1(a) shows a

Manuscript received February 10, 2013; revised May 23, 2013. This work is supported by Blue Scope Buildings Australia. All of the technical support for use of analysis programs and access to the various international design codes was provided by Blue Scope Buildings Australia.

Saleem M. Umair has previously worked as an estimation and design engineer with Kirby Building Systems, Kuwait. Currently, he is doing his PhD from The Department of Civil Engineering, The University of Tokyo, Japan. (email: mumair@iis.u-tokyo.ac.jp).

Hisham. Q. has previously worked as an estimation and design engineer with Kirby Building systems, Kuwait. Currently he is working as a Project Manager with BlueScope Buildings Australia, Manchester Road (west),Auburn, NSW, 2144, (email: hisham.qureshi@bluescopesteel.com).

Zahid A. Siddiqi is a Professor at Department of Civil Engineering, University of Engineering and Technology Lahore, Pakistan (e-mail: zasiddiq@uet.edu.pk). built up section mostly used either as beam or column and Fig. 1(b), (c) and (d) show cold formed channel section, cold formed Z-shape section and roof sheeting respectively.

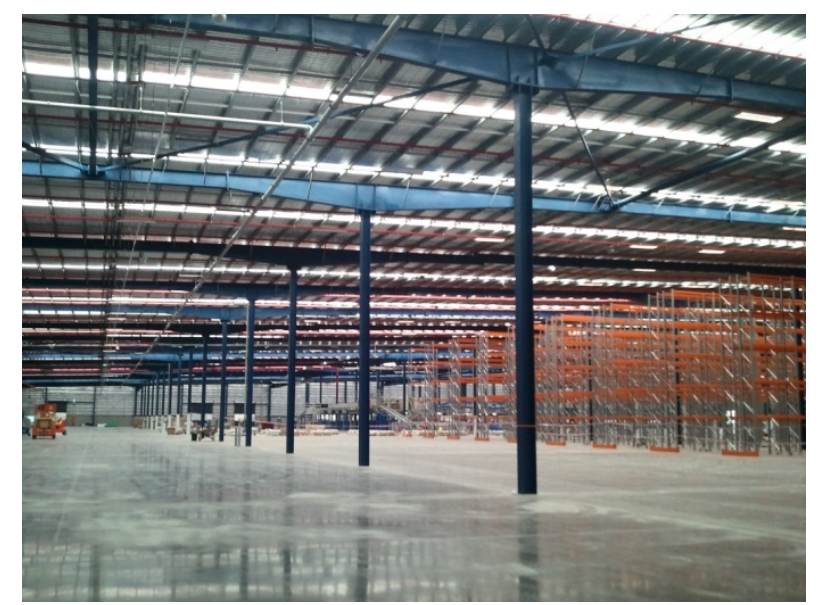

Fig. 1. A typical PEB frame with built up frames and cold formed purlins and roof sheeting.

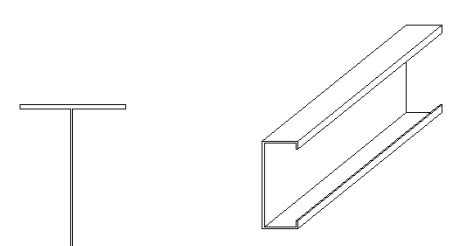

(b)

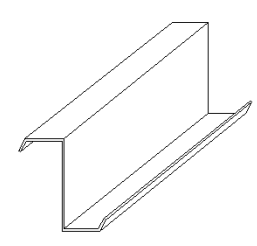

(c)

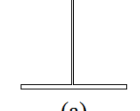

(a)

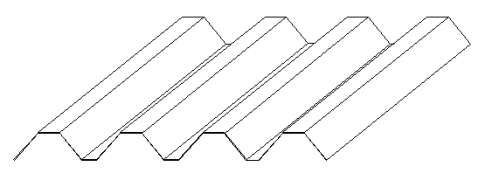

(d)

Fig. 2. Different type of sections used in Pre Engineered Buildings.

In the past, many researchers had worked on slender sections. Cold formed or built up slender sections are thin walled sections and suitable for use in those cases when the members overall buckling failure governs the design and steel members are having very high values of unbraced length ratios (ratio of unbraced length to the total length of member). In case of PEB, interior columns of main frames are fully unbraced as shown in Fig. 1. Slender sections consist of thin wall elements (flanges and webs) which locally buckle at stress level much lower than yield level of steel depending upon the effective width of these elements. Different steel design codes determine the values of effective width based upon the past research. Salem et al. [1] determined the ultimate capacity of I-shaped slender column. He selected a group of slender sections and varied their flange and web thickness ratios and drawn the complete ultimate strength 
curves for selected range of I-sections. He found that ultimate capacity of a section depends upon the interaction of flange and web thickness. Rangelov [2] computed the effective stiffness of slender steel sections to calculate the deflection. $\mathrm{He}$ found that theoretical effective width for stiffness calculation is always greater than the effective width used for strength and suggested an extension of concept of effective width. Hancock et al. [3], [4] determined the effective resistance of axial loaded I-shaped and box section. According to him, effective section method to predict the local and overall buckling interaction is good for heavier webs and gives an uneconomical solution for normal webs. Ellobody et al. [5] investigated the buckling behavior of cold-formed high strength stainless steel stiffened and unstiffened slender square and rectangular hollow section columns. He developed a non-linear finite element method to investigate the behavior of slender square and rectangular columns. He found that stiffened slender steel hollow sections offer better resistance as compared to unstiffened hollow slender sections. Ellobody and Young et al. [6], [7] proposed a numerical model to analyze high strength fixed-ended cold-formed unstiffened rectangular and square hollow stainless steel section columns. They also developed a numerical model to determine the behavior of cold-formed unstiffened slender circular hollow section columns using normal strength stainless steel. Lindstorm et al. [8] carried out experiments on mild steel I-section columns composed of a cross-section that was made of a slender web and thick flanges whereas Kalyanaraman et al. [9] studied the interaction of columns composed of thicker webs and slender flanges and found that interaction of overall and local buckling is also effected by the shape of the column. Wei-Xin Ren et al. [10] also carried out an experimental and numerical study to determine the interaction of local and overall buckling behavior of I-shaped steel column sections. He found that column overall slenderness, local slenderness of section elements and load eccentricity can significantly affect the buckling behavior of columns. According to him, local buckling failure of section elements does not corresponds to complete failure or loss of strength of steel columns.

In this study, optimum value of local web and flange slenderness are determined to get the maximum efficiency and load carrying capacity of a steel section for a given unbraced length of steel member. Different steel sections varying from very compact range to a slender range are selected for analysis and their load carrying capacity is determined. The relation of optimum flange and web local slenderness is also established with the unbraced length ratio of steel members. Current study provides the basis to steel designers to directly select a minimum weight section for a given unbraced length of steel member and contributes towards safe and economical construction.

\section{Design OF SLENDER SECTIONS}

In order to evaluate the capacity of built-up slender web and flanges, chapter $\mathrm{E}$ and $\mathrm{F}$ of American Specification for Structural Steel Buildings ANSI/AISC 360-05 [11] is used. Section E-3 of [11] gives the elastic critical buckling stress of steel section based upon the overall slenderness ration and member end conditions. Equation (1) gives the elastic critical buckling stress.

$$
F_{e}=\frac{\pi^{2} E}{\left(\frac{K L}{r}\right)^{2}}
$$

where $F_{e}=$ critical buckling stress, $E=$ Young's modulus of elasticity of built-up steel and (KL / r) is overall slenderness ratio of steel section.

Section E6 and E7 of ANSI/ASCE 360-05 [11] determines the strength reduction factors $\mathrm{Q}$ to find out the contribution of each section element, and reduction factor is given by (2).

$$
Q=Q_{s} \times Q_{a}
$$

where $Q_{a}=$ strength reduction factor for slender stiffened elements and $Q_{s}=$ strength reduction factor for slender unstiffened elements.

\section{A. Unstiffened Elements-Flanges}

In case of built-up sections with unstiffened flanges, $Q_{s}$ is determined using (3) to (4) depending upon the flange slenderness ratio .

a) If $\frac{b}{t} \leq 0.64 \sqrt{\frac{E k_{c}}{F_{y}}}$ than $Q_{s}=1.0$

b) If $\leq 0.64 \sqrt{\frac{E k_{c}}{F_{y}}}<\frac{b}{t} \leq 1.17 \sqrt{\frac{E k_{c}}{F_{y}}}$ than value of $Q_{s}$ is given by (3).

$$
Q_{s}=1.415-0.65\left(\frac{b}{t}\right) \sqrt{\frac{E k_{c}}{F_{y}}}
$$

c) If $\frac{b}{t}>1.17 \sqrt{\frac{E k_{c}}{F_{y}}}$ than value of $Q_{s}$ is given by (4) as follows:

$$
Q_{s}=\frac{0.90 E k_{c}}{F_{y}\left(\frac{b}{t}\right)^{2}}
$$

where $k_{c}=\frac{4}{\sqrt{h / t_{w}}}, \mathrm{~h}=$ depth of built up section and $\mathrm{t}_{\mathrm{w}}=$ thickness of web.

\section{B. Stiffened Elements-Webs}

$Q_{a}$ factor for the stiffened elements is determined by calculating $h / t_{w}$ and if $\frac{h}{t_{w}}>1.49 \sqrt{\frac{E}{F_{y}}}$ then web is known as slender web than $\mathrm{Q}_{\mathrm{a}}$ is computed by (5).

$$
Q_{a}=\frac{A_{e f f}}{A}
$$

where $A_{\text {eff }}$ is effective area for the stiffened element based upon the reduced effective width. Equation (6) and (7) give the values of effective width and area of stiffened element such as web of built up section. 


$$
\begin{gathered}
b_{e}=1.92 t \sqrt{\frac{E}{f}\left[1-\frac{0.34}{(h / t)}\right]} \leq b \\
A_{\text {eff }}=b_{e} t_{w}+2 b_{f} t_{f}
\end{gathered}
$$

The flexure design of slender built-up section is carried out using Section F of ANSI/ASCE 360-05 [12].

\section{Section AND MAterial Properties}

\section{A. Material Properties and Loading Conditions}

In order to establish relationships between flange local slenderness ratio and unbraced length ratio, a built-up member with $12 \mathrm{~m}$ length is selected. This section is fully unbraced in major direction whereas in minor direction the unbraced length of member is varied in the interval of $2 \mathrm{~m}, 4 \mathrm{~m}$, $6 \mathrm{~m}, 8 \mathrm{~m}, 10 \mathrm{~m}$ and $12 \mathrm{~m}$ which corresponds to unbraced length ratio $(\mathrm{Lb} / \mathrm{L})$ of $0.167,0.33,0.5,0.67,0.833$ and 1.0 respectively. Hinged end conditions are taken on both ends of the member and an axial load of $2500 \mathrm{kN}$ with $900 \mathrm{kN}-\mathrm{m}$ moment in major direction bending is considered. Fig. 3 shows the member profile and directions of loading and Table I gives the material properties and loading conditions of built up steel used in this study.

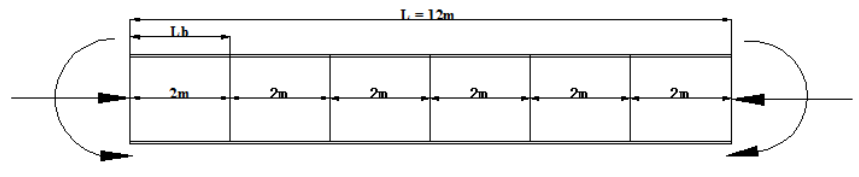

Fig. 3. Built up member profile.

\begin{tabular}{ll} 
TABLE I: MATERIAL PROPERTIES AND LOADING CONDITIONS \\
\hline \hline Property & Value \\
\hline Yield strength of built up steel & $345 \mathrm{MPa}$ \\
Ultimate Strength of built up steel & $450 \mathrm{MPa}$ \\
Length of the member & $12 \mathrm{~m}$ \\
Axial service load (P) & $2500 \mathrm{kN}$ \\
Service moment & $900 \mathrm{kN}-\mathrm{m}$ \\
$\mathrm{Kz}$ & 1.0 \\
$\mathrm{Kx}$ & 1.0 \\
$\mathrm{Ky}$ & 1.0 \\
\hline \hline
\end{tabular}

\section{B. Selected Slenderness Ratio}

Different flanges slenderness ratio are selected varying form a fully compact range 4 to a highly slender value of 16.00. Similarly web slenderness ratios are also varied from 37.50 to 266.67 as shown in Table II. Table II also gives the width of flange $\left(b_{f}\right)$, thickness of flange $\left(t_{f}\right)$, depth of built-up section ( $h$ ) and thickness of web $\left(t_{\mathrm{w}}\right)$. These values are carefully selected based upon the mostly used plate inventory of PEB structures. Required sizes of flange and web are cut from steel plates and joined together with the help of electric welding either on one or both sides of built up section. Fig. 4 gives the details of a typical built up section.

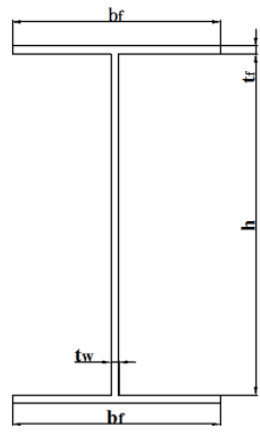

Fig. 4. Built up section profile.

TABLE II: SELECTED FLANGE AND WEB SLENDERNESS RATIOS

\begin{tabular}{cccccc}
\hline \hline \multicolumn{3}{l}{ Flange slenderness ratio } & \multicolumn{3}{c}{ Web slenderness ratio } \\
\hline $\mathrm{b}_{\mathrm{f}}(\mathrm{mm})$ & $\mathrm{t}_{\mathrm{f}}(\mathrm{mm})$ & $\mathrm{b}_{\mathrm{f}} / 2 \mathrm{t}_{\mathrm{f}}$ & $\mathrm{h}(\mathrm{mm})$ & $\mathrm{t}_{\mathrm{w}}(\mathrm{mm})$ & $\mathrm{h} / \mathrm{t}_{\mathrm{w}}$ \\
\hline 240 & 30 & 4.00 & 600 & 16 & 37.50 \\
\hline 300 & 24 & 6.25 & 800 & 12 & 66.67 \\
\hline 360 & 20 & 9.00 & 960 & 10 & 96.00 \\
\hline 400 & 18 & 11.11 & 1200 & 8 & 150.00 \\
\hline 450 & 16 & 14.06 & 1200 & 6 & 200.00 \\
\hline 480 & 15 & 16.00 & 1600 & 6 & 266.67 \\
\hline \hline
\end{tabular}

\section{ANALYSIS RESUlTS AND DisCUSSIONS}

Fig. 5 shows the graph between the flange slenderness and ratio of allowable load carrying capacity to the required service load $(\mathrm{Pa} / \mathrm{P}) . \mathrm{Pa}$ is determined according to ANSI/AISC 360-05 [11] and depends upon the flange and web slenderness ratio whereas $\mathrm{P}$ is required load carrying capacity as given in Table I. All built up section are analyzed by varying their flange slenderness ratio from 4.00 to 16.00 and keeping a fixed value of web slenderness corresponding to $800 \mathrm{~mm}$ web depth and $12 \mathrm{~mm}$ flange thickness which is a slender range of webs. Fig. 5 is plotted under pure compressive effects when no moments are acting on the members. Fig. 5 clearly indicates that for a given unbraced length by increasing the flange slenderness ration capacity increase up to an optimum value and then starts reducing. Similar trend is observed for almost all different unbraced length ratios. By increasing the unbraced length ratio the overall capacity of section also reduces. Even for a highly unbraced length member with ratio of $\mathrm{Lb} / \mathrm{L}=1.00$ compact section reduces the capacity and slender flanges are advisable.

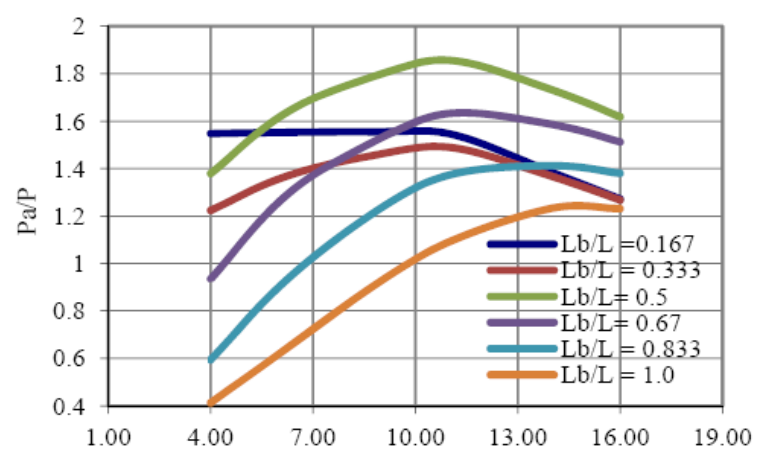

Fig. 5. Variation of flange slenderness ratio for different unbraced length ratio under pure compression. 


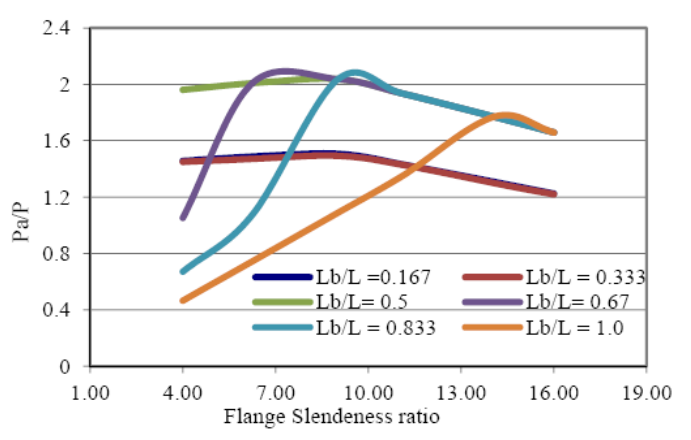

Fig. 6. Variation of flange slenderness ratio for different unbraced length ratio under pure bending.

Fig. 6 shows the variation of $\mathrm{Pa} / \mathrm{P}$ with respect to flange slenderness ratio for different unbraced lengths under bending. Similar type of trend is observed when the unbraced length ratio is very small such as 0.167 or 0.333 as there is no significant decrease in strength is observed. It is due to the fairly good bracing conditions of built up steel section. It is also observed that for higher unbraced length ratios and flange slenderness ratios, the capacity of section becomes almost equal and curves starts overlapping on each other. In Fig. 6, flange slenderness ratios corresponding to the peak values of strength for a given unbraced length ratios are noted as in case of $\mathrm{Lb} / \mathrm{L}=1.00$ the optimum value of flange slenderness value is 15 . Similarly the optimum values of flange slenderness are noted for all unbraced length ratios for bending and compression using Fig. 5 and Fig. 6.

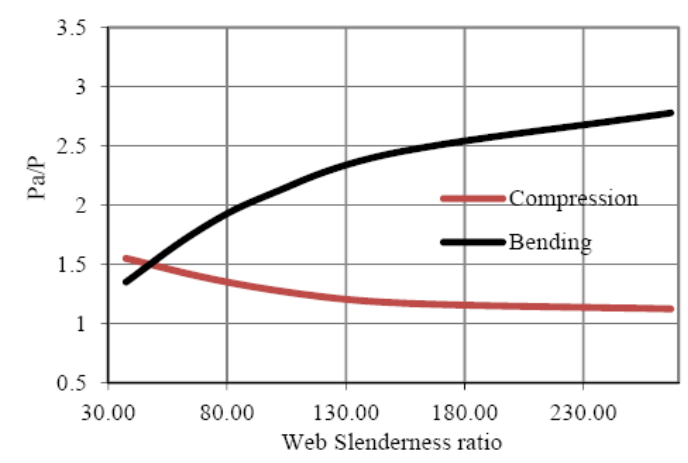

Fig. 7. Variation of web slenderness under compression and bending.

Fig. 7 shows the variation of $\mathrm{Pa} / \mathrm{P}$ with respect to web slenderness ratio for a constant unbraced length ratio of 0.834 and a constant flange slenderness ratio of 14.06 which are corresponding to the conditions when member is overall slender and also having locally unstable flanges. Fig. 7 also shows that by increasing the web slenderness, bending capacity of section increase but compression capacity of section reduces. This effect is opposite for smaller values of web slenderness. At a slenderness ratio 66.66 the capacity in both of the cases becomes equal to each other. So, a designer should be careful for selection of web slenderness. He should understand that which effect is more dominant in a given steel structural member and should select the section accordingly.

Fig. 8 gives the optimum values of flange slenderness for a given value of unbraced length ratio for both bending and compression. This curves shows that for smaller unbraced length ratios varying from 0.2 to 0.6 , non-compact range of flange slenderness is preferable. As the unbraced length of a member increases, overall slenderness also increases which allows using flanges in slender range. From unbraced length ratio of 0.6 to 1.0 the use of slender flanges gives high strength at the rate of lower cost.

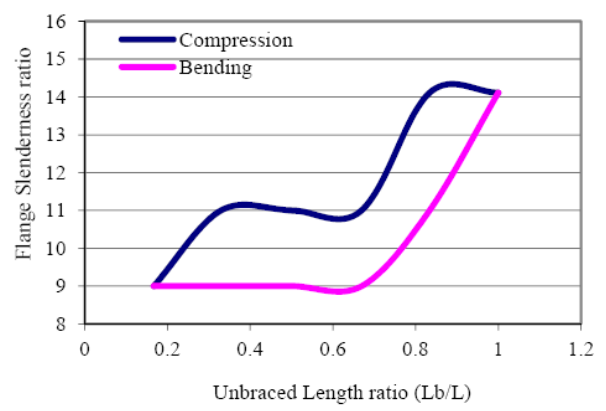

Fig. 8. Optimum values of flange slenderness ratio with respect to unbraced length ratio.

\section{CONCLUSIONS}

Results of current study give the ultimate load carrying capacity of a wide range of sections with different values of flange slenderness ratio, web slenderness ratio and unbraced length ratio which control the overall slenderness ratio of a structural member. It is also observed that use of thin walled sections with a good theoretical background knowledge and understanding of variation of local slenderness ratio with respect to overall slenderness ratio may lead to a safe and highly economical design. This study shows that always the use of compact flanges and webs is not advisable as in case of higher unbraced length ratios the use of compact section even has adverse effect as shown in Fig. 5 and Fig. 6. It is also found that there is an interaction between the overall slenderness ratio and local slenderness ratio of built up section elements. For small unbraced length ratios the steel members with thick flanges are preferable whereas for high unbraced length ratio where overall slenderness ratio of the members governs the design, use of slender elements may lead to a good design with minimum weight of the section.

\section{REFERENCES}

[1] A. H. Salem, M. El Aghoury, F. F. El Dib b, and M. T. Hanna, "Ultimate capacity of I-slender section columns," Journal of Constructional Steel Research, vol. 60, pp. 1193-1211, 2004.

[2] N. Rangelov, "On the effective stiffness of slender steel sections for deflection calculations," Thin-Walled Structures, vol. 25, no. 3, pp. 171-183, 1996.

[3] G. J. Hancock, "Nonlinear analysis of thin sections in compression," Journal of Struct Engng ASCE, vol. 107, pp.455-471, 1981.

[4] G. J. Hancock, "Interaction buckling in I-Section columns," J. Struct. Engng. ASCE, vol. 107, pp. 165-179, 1981.

[5] E. Ellobody, "Buckling analysis of high strength stainless steel stiffened and unstiffened slender hollow section columns," Journal of Constructional Steel Research, vol. 63, pp. 145-155, 2007.

[6] E. Ellobody and B. Young, "Structural performance of cold-formed high strength stainless steel columns," Journal of Constructional Steel Research, vol. 61, pp. 1631-1649, 2005.

[7] B. Young and E. Ellobody, "Column design of cold-formed stainless steel slender circular hollow sections," Steel and Composite Structures, vol. 6 , no.4, pp. 285-302, 2006.

[8] G. Lindstrom, "Column strength of welded I-sections in post buckling range of component plates," Bulletin Number 138, Stockholm: The Dept. of Structural Mechanics \& Engineering, Royal Institute of Technology; 1982.

[9] V. Kalyanaraman, T. Pekoz, and G. Winter, "Unstiffened compression elements," J. Struct. Engng ASCE, vol. 103, pp. 1083-848, 1977.

[10] W. X. Ren and Q. Y. Zeng, "Interactive buckling behavior and ultimate load of I-section steel columns," J. Struct. Engng. ASCE, vol. 123, no. 9, pp. 1210-1217, 1997. 
[11] Design of members for compression, ANSI/ASCE 360-05, American Standard, pp. 32-42, 2005.

[12] Design of Members for Flexure, ANSI/ASCE 360-05, American Standard, pp. 44-63, 2005.

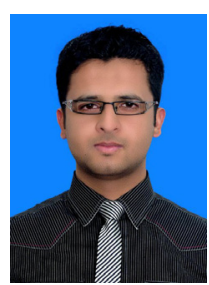

Saleem M. Umair is a graduate of Structural Engineering from University of Engineering and Technology Lahore. He born in 1985 in Lahore, Pakistan and completed his B.Sc in Civil Engineering in 2007 with honors. He finished his M.Sc in structural engineering in 2009. He is goldmedalist in the subjects of structural engineering and hydraulics and public health engineering.

He worked as a lecturer in Department of Civil Engineering, The University of Engineering and Technology Lahore from 2007 to 2008. At the end of 2008, he joined Kirby building Systems Kuwait and worked as an estimation and design engineer.
Umair started his PhD in 2010 from Department of Civil Engineering, The University of Tokyo. He won the excellent paper award from JAEE Japan Association of Earthquake Engineering. He is the member of JAEE and bears the membership of Pakistan Engineering Council.

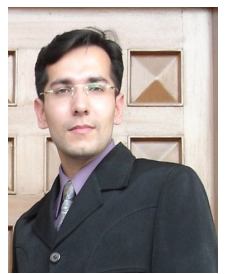

Hisham Qureshi is a graduate of Structural Engineering from University of Engineering and Technology Lahore. He completed his B.Sc in Civil Engineering in 2007 and have studied advanced master courses in the field of Structural Engineering from The University of Adelaide,Australia. Currently he is doing his masters degree in Structures from University of Technology,Sydney.

Hisham worked previously with Kirby building Systems Kuwait as an estimation and design engineer and currently he is working with BlueScope Buildings Australia as a Project Manager. 